\title{
LAS DOS BESTIAS DE APOCALIPSIS 13
}

\author{
Segundo Teodomiro Azo Salazar \\ sazodoc@gmail.com \\ Universidad Peruana Unión
}

Resumen $\mid$ Profecía bíblica es un tema requerido por la cristiandad, y los temas apocalípticos son los que más dificultad generan en cuanto a su interpretación. El propósito de este estudio es identificar y describir las bestias de Apocalipsis 13, la metodología del estudio toma como base los principios de interpretación historicista, y como proceso de trabajo toma en cuenta el análisis exegético, gramatical y teológico. Se ha llegado a la conclusión de que en Apocalipsis 13 se identifica a la primera bestia como la representación del papado y la segunda bestia es la forma simbólica de Estados Unidos.

Palabras clave: Bestias de apocalipsis, profecía apocalíptica, Apocalipsis 13. 


\section{THE TWO BEASTS OF REVELATION 13}

Bible prophecy is a required subject by Christianity, and apocalyptic themes are those that generate more difficulty in their interpretation. The purpose of this study is to identify and describe the beasts of Revelation

13, the study methodology builds on the principles of historicist interpretation, and as a work process takes into account the exegetical, grammatical and theological analysis. It has come to the conclusion that in Revelation 13 the first beast as representing the papacy and the second beast is the United States symbolically identified.

Keywords: Beasts of apocalypse, apocalyptic prophecy, Revelation 13. 


\section{Introducción}

La identificación de las dos bestias de Apocalipsis 13, por parte del vidente de Patmos (Ap 1:910), ha suscitado diferentes interpretaciones de parte de eruditos y miembros de diferentes denominaciones religiosas, dependiendo de los principios de interpretación que han sido utilizados para su análisis. Los preteristas ${ }^{1}$ han visto en las bestias de Apocalipsis 13, a alguno de los emperadores romanos del primer siglo como Calígula, Tito, etc. En tanto que intérpretes futuristas ${ }^{2}$ han ubica-

${ }^{1}$ Los preteristas ubican esos acontecimientos en el siglo I d. C., en el período de la Roma imperial. Tal como señala J. M. Ford, "los monstruos representan al Imperio romano y a quienes cooperan con él". En cuanto a los 42 meses de la autoridad de la bestia, Ford lo relaciona, por paralelismo, con la persecución de los judíos a manos de Antíoco Epífanes...o con la profanación del templo de Jerusalén, ya sea por parte de Calígula o de Tito (o de ambos). J. Massyngberde Ford, Revelation (Nueva York: Doubleday and Company, 1975), 218.

${ }^{2}$ Los futuristas dispensacionalistas coinciden en que se trata del Imperio romano resurgido en el tiempo del fin, no el Imperio romano de los días de Jesús o de los apóstoles...La descripción según Walvoord encaja en el tiempo durante la gran tribulación de la última semana de Daniel 9:27. Walvoord, The Revelation of do a las bestias de Apocalipsis 13 en la septuagésima semana de la profecía de Daniel 9:27 al aplicar al anticristo de los últimos días la obra de las bestias de Apocalipsis.

El propósito de este estudio es mostrar a través del principio de interpretación historicista ${ }^{3}$ usado por Juan en el Apocalipsis, así como a través de un análisis exegético, gramatical y teológico, que la primera bestia de Apocalipsis 13 es el poder de Roma en su fase pagana y papal y la segunda bestia representa a los EE.UU. de Norteamérica como la nación que le haría una imagen a la primera bestia, imponiendo una marca, persiguiendo al último remanente y dando un decreto de muerte, sobre la base de que ambas recibieron todo su poder del Dragón $(13: 2,12)$.

\footnotetext{
$\overline{\text { Jesus Christ, 197-98. }}$

${ }^{3}$ Los intérpretes historicistas identifican a la primera bestia también con Roma. Sin embargo, dados los aspectos manifiestamente religiosos de su carácter y actividades, es identificada con la fase religiosa de la actividad romana, epitomizada en el papado. Frank B. Holbrook, ed. Simposio sobre Apocalipsis-I (Florida: Asociación Publicadora Interamericana, 2010), 415.
} 


\section{Contexto de Apocalipsis 13}

El capítulo 13 del Apocalipsis se encuentra ubicado estructuralmente en el corazón mismo del libro, conformado por los capítulos 11:19 a 14:20 denominado por Maxwell ${ }^{4}$ gran conflicto; mientras que K. A. Strand ${ }^{5}$, después de presentar toda una estructura quiástica del libro de Apocalipsis, denomina a esta sección central como "los poderes del mal, opuestos a Dios y sus santos". A continuación se detalla la estructura general del libro de Apocalipsis para poder apreciar mejor el capítulo que es motivo de estudio:

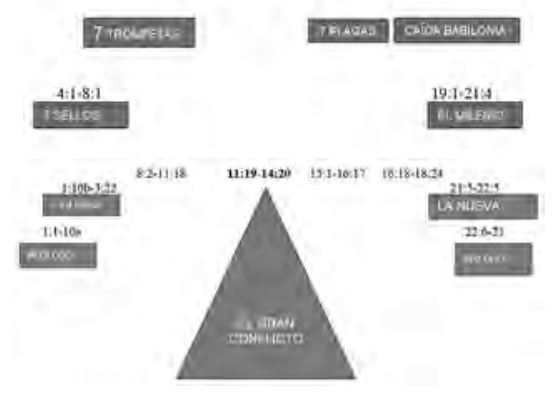

${ }^{4}$ C. Mervyn Maxwell, Apocalipsis sus revelaciones (Buenos Aires: Asociación Casa Editora Sudamericana, 1989), 310.

${ }^{5}$ Kennet A. Strand, Symposium on Revelation, ed. Frank B. Holbrook (Silver Spring, MD: Biblical Research Institute, 1992), 1: 36-37.
Como se puede apreciar en la estructura anterior, el capítulo 13, motivo de este artículo, se encuentra enclavado en la sección denominada "el gran conflicto", entre la profecía de las siete trompetas y las siete postreras plagas.

Estudiosos como Strand ${ }^{6}$ han dividido el libro de Apocalipsis en dos partes: la parte histórica conformada por los capítulos 1 al 12, y la parte profética, conformada por los capítulos 13 al 22 del mismo. Esto indica que el capítulo 13 estaría al final de la parte histórica y dando inicio a la parte profética.

Es importante señalar que en la literatura apocalíptica, de los libros de Daniel y Apocalipsis, los escritores hicieron uso del principio de interpretación historicista, al mencionar el desarrollo de los acontecimientos históricos desde sus días hasta el esjaton (últimos días), a través del surgimiento y caída de los imperios mundiales desde Babilonia, Medo Persia, Gre-

${ }^{6}$ Kennet A. Strand, “The Eight Basic Visions in the Book of Revelation" Andrews University Seminary Studies 25, (1987): 107-121. 
cia, Roma, hasta el reino de Cristo (Dan 2, 4, 7, 8, 11). Este mismo principio se puede ver en el capítulo 12 de Apocalipsis, donde el escritor resume la historia en solo 17 versículos, desde el nacimiento del Mesías siglo I (Ap 12:1-5), pasando por la edad media del período de los 1260 días o años proféticos (v. 6, 14), hasta el surgimiento del último remanente que guardaría los mandamientos y tendría el testimonio de Jesucristo (v. 17). ${ }^{7}$ Véase a continuación sobre la línea cronológica del capítulo 12 de Apocalipsis como el escritor 102 de Apocalipsis resume los eventos históricos desde sus días, hasta el último remanente profético:

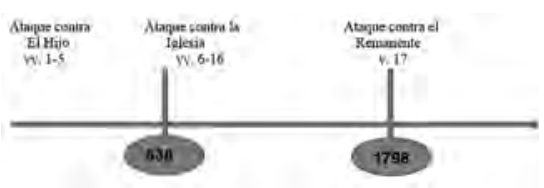

En este contexto, el capitulo 13 es el desarrollo de la guerra del dragón contra el remanente, mientras que el capítulo 14 es la respuesta del

${ }^{7}$ William H. Shea, Simposio sobre Apocalipsis, Frank B. Holbrook ed. (Florida: Asociación Publicadora Interamericana, 2010), 1: 387-425. remanente contra el ataque del dragón. ${ }^{8}$

Antes de introducir de lleno el desarrollo del capítulo 13, es necesario identificar el contexto histórico en el cual se desarrolla la guerra del dragón contra el remanente de Dios desde los días de Juan (siglo I), hasta el último remanente que existiría en los últimos días.

\section{Contexto histórico de Apocalipsis}

El testimonio de los primeros escritores cristianos es casi unánime, en el sentido de que el libro de Apocalipsis fue escrito durante el reinado del emperador Domiciano (81-96 d. C.). El escritor Victoriano quien murió cerca al año $303 \mathrm{~d}$. C. dice: "Cuando Juan vio estas cosas en la isla de Patmos, condenado a la labor de las minas por el César Domiciano, allí vio el Apocalipsis" (Padres Antenícenos, Tomo VII, pág. 353). ${ }^{9}$

${ }^{8}$ John Paulien, What the Bible Says About the End Time (Hagerstown, MD: Review \& Herald Publishing Assn, 1998), 109.

${ }^{9}$ Donald McFayden. “The Ocasión 
Eusebio de Cesarea, quien vivió aproximadamente por el 320 d. C., registra que Juan fue enviado a Patmos por Domiciano y fue soltado por su sucesor Nerva (Historia Eclesiástica libro III, párrafo 20 , vers. 8,9$).{ }^{10}$

"De entre todos los emperadores, se puede considerar a Domiciano como uno de los más crueles y perversos. Trató de establecer un gobierno absoluto. Promovió su "divinización" por medio de holocaustos públicos: quemaban cristianos como antorchas vivientes y, a su luz los otros cristianos, eran destrozados por fieras hambrientas en el circo romano". ${ }^{11}$

Es en este contexto histórico, de persecución que el emperador Domiciano, tomó prisionero al apóstol Juan y lo hizo traer a Roma donde dio testimonio de su

of the Dominiatic Persecution" Americam Journal of Theology, 14 (2009):45-66.

${ }^{10}$ Eusebius of Caesarea, An Ecclesiastical History to the 20th Year of the Reign of Constantine (London: Samuel Bagster and Sons, 1847), 122.

${ }^{11}$ Donald McFayden. "The Ocasión of the Dominiatic Persecution" Americam Journal of Theology, 14 (2009): 4566. amor por Cristo. Sus argumentos eran contundentes, convincentes y Domiciano, lleno de ira, mandó que lo arrojaran en una caldera llena de aceite hirviente, pero el Señor Jesús preservó la vida de su siervo. $^{12}$

Más tarde, por decreto de ese mismo emperador, Juan fue enviado a la isla de Patmos, una isla rocosa que forma parte del archipiélago griego y que se encuentra cerca de la costa de la Turquía actual. A este lugar se enviaba a los delincuentes para que murieran trabajando como bestias en trabajos forzados.

Fue aquí, alrededor de los años 95 y 96 de nuestra era, en un día sábado "en el día del Señor"13, que Jesús visitó a Juan su amigo para mostrarle "las cosas que deben suceder pronto...y las que han de ser después de estas"14. Realmente Juan nunca estuvo solo, su amado Maestro no solo

${ }^{12}$ Elena G. de White, Hechos de los apóstoles (Buenos Aires: Asociación Casa Editora Sudamericana, 1995), 554556.

${ }^{13}$ Apocalipsis 1:10.

${ }^{14}$ Apocalipsis 1:1,19. 
estaba con él, sino también con su Iglesia que se encontraba ante la más fiera amenaza de la persecución y necesitaba de una nueva revelación de Jesucristo. Por lo tanto, las visiones reveladas a Juan llenaban una necesidad específica de aliento y fortaleza para los cristianos que se negaban a adorar al emperador y, de manera especial, para los cristianos de los últimos tiempos que vivirían esta misma experiencia, antes de encontrarse con Jesús en su segunda venida.

Es en el contexto de persecución, por negarse a adorar al emperador Domiciano como "Señor y Dios", que Juan fue condenado a morir quemado en un perol de aceite hirviendo y luego deportado a la isla de Patmos. Por ello, no es raro que en los capítulos 12 al 14 de Apocalipsis Juan repita hasta en ocho ocasiones la palabra griega proskunéo ("yo adoro"), para mostrar que el tema principal, en el gran conflicto, es el tema de la adoración.

\section{Interpretación histórica gramatical y teológica de Apocalipsis 13}

Cuando se trata de interpretar la profecía apocalíptica, hay que tener en cuenta que Juan utiliza más de 300 referencias bíblicas del Antiguo Testamento, especialmente del libro de Daniel. Téngase en cuenta que habían profecías daniélicas que tendrían su cumplimiento en el tiempo del fin. Es por ello que se le ordenó a Daniel "sella el libro hasta el tiempo del fin” (12:4).

Para una interpretación seria, del libro de Apocalipsis, se tendrá en cuenta aquí los siguientes principios $^{15}$ de interpretación (hermenéutica):

1. Los temas del Apocalipsis están estrechamente relacionados con los de Daniel, y también con los temas de Mateo 24-25 y 2 Tesalonicenses 2 .

${ }^{15}$ Frank B. Holbrook, ed. Simposio sobre Apocalipsis (Florida: Asociación Publicadora Interamericana, 2010), 2: 58-61. 
2. Las profecías fundamentales del Apocalipsis, como las de Daniel, Mateo 24-25 y 2 Tesalonicenses 2, tienen mucho en común: (a) se extienden desde los días del profeta hasta la segunda venida de Cristo; (b) tratan, fundamentalmente, sobre los aspectos más ásperos de las entidades políticas y político-religiosas; (c) advierten de una apostasía y una persecución sin precedentes; y (d) prometen un desenlace cristocéntrico con recompensa para los justos y destrucción para los malvados.

3. El enfoque historicista es la única clave justificable para interpretar las profecías que hablan de muchos "días" y "semanas". La prueba de que un día en tales profecías representa un año natural y de que una semana representa siete años naturales es abundante en las Escrituras ( $\mathrm{Ez}$ 4:6; $\mathrm{Nm} \mathrm{14:34).}$
4. Cuando Daniel, Mt 2425, 2 Tesalonicenses $2 \mathrm{y}$ el Apocalipsis abordan, desde el punto de vista profético, las entidades religiosas y políticas más importantes, se centran de manera selectiva en aquellas entidades que afectan de manera más directa a los adoradores de Dios.

5. El Apocalipsis con sus numerosos "septetos", sus símbolos asombrosos, sus expresiones reiterativas, sus estructuras literarias, es una obra maestra. Por ello, debe prestarse la debida atención a la estructura literaria. El estudio de la marca de la bestia se verá ayudado por la consideración de elementos como "las escenas introductorias en el santuario". ${ }^{16}$

${ }^{16}$ Strand, sostiene que cada una de las ocho divisiones del Apocalipsis es introducida por una escena del santuario (Ap 1:10b-20; 4-5; $8: 2-6 ; \quad 11: 19 ; \quad 15: 1-16: 1 ; \quad 16: 18-17: 3 a$ 19:1-10; 21:5-11a). Véase Holbrook, 1: $48-49$. 
6. Dios no hace acepción de personas (Hch 10:34), y la profecía no es de interpretación privada (2 P 1:20), por lo que no debe pasarse por alto las interpretaciones proféticas ofrecidas por los estudiosos de la Biblia del pasado, teniendo en cuenta que algunos aspectos de las profecías de Daniel quedaron sellados por Dios hasta el final de los 1,260 días (Dn 12; Ap 10).

7. Los escritos de Elena G. do ser una gran bendición para millones de personas de distintas confesiones. Los adventistas del séptimo día no debieran privarse de algo que otros aprecian especialmente en la actualidad, cuando un desafío tras otro sirve para poner más de manifiesto la inspiración de esa autora. En consecuencia, las interpretaciones de Elena G. de White deberían tomarse en serio si escribió

sobre el asunto, objeto de estudio.

$\mathrm{Si}$ se tiene en cuenta que, estructuralmente, cada una de las visiones del Apocalipsis es introducida por una escena del santuario, la sección del Apocalipsis relativa al gran conflicto, es decir, los capítulos 12-14, comienza en realidad con el versículo final del capítulo 11:19. En esta escena introductoria del santuario, Juan contempla el arca en el lugar santísimo del cielo. Con ello se centra la atención en la ley de Dios como asunto principal de la división del gran conflicto. Maxwell sostiene que es imposible sobreestimar la importancia de esta escena del santuario, para la interpretación de la marca de la bestia. ${ }^{17}$

\section{Interpretación de Apocalipsis 13}

Téngase en cuenta que el capítulo 13 de Apocalipsis es una continuación del ataque del dragón

${ }^{17}$ Maxwell, Simposio sobre Apocalipsis, Frank B. Holbrook, ed. (Florida: Asociación Publicadora Interamericana, 2010), 2: 62. 
contra el remanente (Ap 12:17), utilizando para ello a dos de sus agentes, la primera y la segunda bestia, con quienes conforma la falsa trinidad.

Para un mejor análisis del capítulo, este ha sido dividido en secciones bien marcadas, tal como lo presenta el texto griego ${ }^{18}$ en la lengua original:

\section{Primera sección 13:1-4- Descripción de la bestia}

"Me paré sobre la arena del mar, y vi subir del mar una bestia que tenía siete cabezas y diez cuernos; y en sus cuernos diez diademas; y sobre sus cabezas, un nombre blasfemo. Y la bestia que vi era semejante a un leopardo, y sus pies como de oso, y su boca como boca de león. Y el dragón le dio su poder y su trono, y grande autoridad. Vi una de sus cabezas como herida de muerte, pero su herida mortal fue sanada; y se ma-

${ }^{18}$ Kurt Aland, ed. The Greek New Testament, 3ra. Edición (Munster, Westphalia: Institute for New Testament Textual Research, 1975), 866-69. ravilló toda la tierra en pos de la bestia, y adoraron al dragón que había dado autoridad a la bestia, y adoraron a la bestia, diciendo: ¿Quién como la bestia, y quién podrá luchar contra ella?

Gramaticalmente la primera sección está definida por la presencia de dos verbos "vi" (vv. 1 y 2) para describir lo que Juan vio acerca de la primera bestia. Las primeras partes que emergen son las cabezas y los cuernos: los cuernos tienen coronas y las cabezas tienen sobre si el nombre de la blasfemia. Acto seguido se ve su cuerpo, que se asemeja a un leopardo; y sus pies, que son como los de un oso, son lo último en verse. Pero luego la atención del profeta se dirige a la boca, en razón de lo que hablaría la bestia como un elemento importante en la sección explicativa de la visión. La escena siguiente pasa a describir lo que el dragón le dio a la primera bestia: poder, un trono y gran autoridad. Acto seguido la atención de Juan queda captada por una de las cabezas. Seis de las siete tenían un aspecto sano, pero una de ellas había sido herida de muerte. Pero la herida 
había cicatrizado ya, y también la cabeza había vuelto a vivir. ${ }^{19} \mathrm{El}$ pasaje cierra la sección con el verbo prosekunesan "adoraron" al dragón y a la bestia (v. 4).

Juan estaba de pie sobre la arena del mar donde había mucha agua. "las aguas que has visto, donde la ramera se sienta, son pueblos, muchedumbres, naciones y lenguas" (Ap 17:15). Esto significa que la bestia que sube del mar tiene mucha gente como la base de su poder. Estas gentes están organizadas bajo una estructura simbolizada por siete cabezas y diez cuernos, que indican entidades políticas y de poder a través de las cuales el dragón actúa (17:313).

¿Quién es esta primera bestia que subía del mar con cuerpo de leopardo, pies de oso y boca de león? Siendo que la Biblia es su propio intérprete, hay que interpretar la visión en el contexto del libro de Daniel, especialmente el

${ }^{19}$ Véase la división en secciones propuesta por William H. Shea en Holbrook, ed. Simposio sobre Apocalipsis, 2: 415-423. capítulo 7:3-8, donde se describe a los cuatro reinos que se levantarían sobre la tierra (v. 17): Babilonia (605-539 a. C.), Medo Persia (539-331 a. C.) Grecia (331-168 a. C.) y Roma (168 a. C. - 476 d. C.). Sin embargo, Daniel mismo quiso saber acerca de la cuarta bestia "espantosa y terrible" (v. 19) y "de los diez cuernos que tenía en su cabe$z a, y$ del otro (cuerno) que le había salido, delante del cual habían caído tres" (v. 20). En el contexto de Daniel 7 la primera bestia de Apocalipsis 13:1-10 es el cuerno pequeño (Roma en su fase papal).

Siendo que en ambos casos el poder que sigue a Grecia es Roma $(2: 40 ; 7: 7)$ es de suponer que en el capítulo 8, el cuerno pequeño también se aplica a Roma, ya que aquí se habla del tiempo cuando había de surgir este poder. La aparición del cuerno pequeño, después de Grecia, representa a Roma en sus dos fases: pagana y papal, porque la fase pagana se inició después de Grecia, mientras que la fase papal se extendería hasta el fin.

William Shea ${ }^{20}$, comentando

${ }^{20}$ Frank B. Holbrook, Symposium 
Daniel 8, describe la expansión horizontal del cuerno pequeño: cuando dice que el cuerno pequeño creció mucho al sur (Egipto y África) y al oriente (Grecia y Asia) y hacia la tierra gloriosa (Jerusalén en Palestina). Esta expansión terrenal se refiere a la fase pagana de Roma, mientras propagaba su imperio a través de toda la tierra. Históricamente esto es lo que han hecho papas como Pablo VI, Juan Pablo II y últimamente el papa Francisco I, quienes han reunido a líderes mundiales de las tres religiones más grandes del mundo (judíos, islámicos y cristianos evangelios y ortodoxos) para procurar la unidad de las iglesias propuesta por el Concilio Vaticano II de $1960 .{ }^{21}$

Otra descripción, que identifica a la primera bestia con Roma, es que tiene "siete cabezas y diez cuernos”, lo mismo que el dragón

on Daniel (Hagerstown, Maryland: Review and Herald Publishing Association, 1986), 2: 505-509.

${ }^{21}$ Véase el último viaje del papa Francisco a Jerusalén y su diálogo ecuménico con los líderes de las tres religiones más grandes del mundo.
(Ap 12:3). A Juan le fue revelado que estas "siete cabezas son siete montes sobre los cuales se sienta la mujer" y "los diez cuernos que has visto, son diez reyes" (Ap 17:9, 12). Las "siete cabezas" representan a toda la oposición política al pueblo y a la causa de Dios a través de toda la historia, sin especificar qué naciones en particular, ya que el número siete tiene muchas veces un valor más simbólico que literal. Entre las más conocidas estarían: Egipto, Asiria, Babilonia, Persia, Grecia, la Roma pagana, la Roma papal, etc. Los "montes" son un símbolo profético común para designar poderes políticos $\mathrm{o}$ político-religiosos. ${ }^{22}$ Este símbolo también puede ser una alusión a la ciudad de Roma con sus siete colinas, toda vez que los escritores clásicos a menudo se refirieron a Roma como la ciudad de las siete colinas. $^{23}$

${ }^{22}$ Isaías 2:2,3; Jeremías 17:3; 31:23; Ezequiel 17:22,23.

${ }^{23}$ Virgilio, Eneida vi, 782-784; Cicerón, Cartas a Ático vi. 5. Citado por Francis Nichol, ed. Comentario Bíblico Adventista del Séptimo Día (Buenos Aires, Argentina: Asociación Casa Editora Sudamericana, 1990), 7:868. 
Lo más impresionante de la visión está expresada por la repetición del verbo "Vi una de sus cabezas como herida de muerte, pero su herida mortal fue sanada" (13:3). Otra vez el profeta Daniel es la clave para interpretar cuándo y cómo es que Roma sufrió esta herida mortal en el contexto del poder, trono y grande autoridad recibida del dragón (v. 2).

Habiendo identificado a la primera bestia, con el cuerno pequeño o Roma en su fase papal, Daniel declaró que "delante de él (cuerno pequeño) fueron arrancados tres cuernos de los primeros" (Dn 7:8). Estos tres cuernos derribados históricamente fueron arrianos y son identificados con los Hérulos (495 d. C.), los Vándalos (534 d. C.) y los Ostrogodos quienes el 538 (d. C.) dejaron de existir como tribu. ${ }^{24}$ Por tanto, como lo declara Maxwell ${ }^{25}$ lo estipulado por la profecía se había cumplido ya en

${ }^{24}$ C. Mervyn Maxwell, "An Exegetical and Historical Examination of the 1260 Days of Prophesy". Citado por Holbrook, ed. Simposio sobre Apocalipsis, 2: 91-96.

${ }^{25}$ Ibíd., 96.
538 d. C. fecha en que Justiniano emperador romano de oriente declaró al obispo de Roma Virgilio como "cabeza visible de todas las iglesias y corrector de herejes" y podían iniciarse los 1260 años de supremacía papal que finalizarían en 1798 cuando el general Alexandre Berthier invadió Roma y tomó prisionero al papa Pío VI, llevándolo cautivo a Francia, muriendo en el destierro, cumpliendo la profecía que decía: "...si alguno mata a espada, a espada debe ser muerto" (Ap 13:10), eliminando de este modo los poderes políticos y eclesiásticos de Roma. De esta manera Roma, a través de su obispo, sufrió históricamente una herida mortal, la misma que Juan vio que sería sanada, cuando en 1929, con el tratado de Letrán firmado por Benito Mussolini, se le devolvió al papado el gobierno de la ciudad del Vaticano, restaurando su poder político. Pero Juan vio una restauración mayor aún, vio que "se maravilló toda la tierra en pos de la bestia", acrecentándose de este modo su poder en todo el mundo como muestra de que la Roma papal se ha propuesto recuperar 
toda la autoridad que tuvo durante la edad media, lo que cumplirá en su unión de iglesia y estado, juntamente con la segunda bestia de Apocalipsis 13:11.

Así, identificada la primera bestia con el poder de Roma en sus dos fases pagana y papal, la siguiente sección explicará lo que haría Roma como agente del dragón.

\section{Segunda sección- Explicación de lo que dice o hace la bestia (vv. 5-10)}

También se le dio boca que hablaba grandes cosas y blasfemias; y se le dio autoridad para actuar cuarenta y dos meses. Y abrió su boca en blasfemias contra Dios, para blasfemar de su nombre, de su tabernáculo, y de los que moran en el cielo. Y se le permitió hacer guerra contra los santos, y vencerlos. También se le dio autoridad sobre toda tribu, pueblo, lengua y nación. Y la adoraron todos los moradores de la tierra cuyos nombres no estaban escritos en el libro de la vida del Cordero que fue inmolado desde el principio del mundo. Si alguno tiene oído, oiga. Si alguno lleva en cautividad, va en cautividad; si alguno mata a espada, a espada debe ser muerto. Aquí está la paciencia y la fe de los santos.

La segunda sección es inconfundible por su contenido verbal. Contiene cuatro oraciones que comienzan con la frase kai edothe auto ("y se le dio..."). La expresión aparece dos veces en el versículo 5 y otras dos en el versículo 7. Cada vez la expresión introduce algo que es dado a la bestia. Lo primero que se le da es una boca que habla grandes cosas y blasfemias. La segunda es autoridad. La tercera es la capacidad de hacer guerra contra los santos. Y la cuarta es la autoridad sobre las naciones. ${ }^{26}$ Esta sección, al igual que la primera, se cierra con el verbo proskunesusin "y adorarán" a la bestia todos los moradores de la tierra (v. 8).

¿Cuáles son las blasfemias que el poder de Roma ha hecho contra Dios y su verdad? En primer lugar,

${ }^{26}$ Ibíd., 419. 
hay que entender que blasfemia es una injuria contra Dios, de alguien que se atribuye prerrogativas que solo le pertenecen a Dios.

Si se analiza el texto de Apocalipsis 13:1, 5-7, en el contexto de Daniel 7:25 y 2 Tesalonicenses 2:3-10, se verá que tanto Daniel, Pablo y Juan recibieron visiones en cuanto a las blasfemias que el cuerno pequeño haría contra Dios, su santuario y sus santos.

Intérpretes historicistas como M. Moore ${ }^{27}$ señalan varias declaraciones y enseñanzas del papa-

112 do que cumplen la predicción de Daniel de que el cuerno pequeño hablaría "palabras contra el Altísimo". Una de estas es la aseveración de que el papa es el vicario de Cristo. La palabra "vicario" significa "sustituto". Por tanto, el papa declara ser el representante personal de Cristo sobre la tierra, atribuyéndose una prerrogativa que Cristo le confirió al Espíritu Santo como su representante (Jn

${ }^{27}$ Marvin Moore, ¿Será que podría pasar? Apocalipsis 13 a la luz de la historia y los sucesos actuales (Florida: Asociación Publicadora Interamericana, 2008), 35-36.
14:16-18). Las otras dos aseveraciones serán suficientes para mostrar que el papado cumple la predicción de Daniel. Esta es la aseveración que, por medio del rito de la confesión, los sacerdotes católicos tienen el poder de perdonar pecados, una prerrogativa única de Dios (Mr 2:7-10). Y la otra es la afirmación de que el sacerdote sacrifica el cuerpo y la sangre literales de Cristo en el altar durante la misa, contradiciendo de este modo el mensaje del libro de Hebreos de que Cristo ofreció un solo sacrificio para siempre (Heb 9:25-26).

Cuando Daniel, Pablo y Juan hablan del cuerno pequeño, el asombro de estos escritores bíblicos tuvo que ver con el atentado más grande que este agente de Satanás hizo al atacar verticalmente el santuario del cielo, específicamente la obra mediadora de Cristo como Sumo Sacerdote.

Ataque horizontal y Vertical del Cuerno Pequeño

Hablando del cuerno pequeño, Daniel declaró: "y se engrandeció 
hasta el ejército del cielo; y parte del ejército y de las estrellas echó por tierra y las pisoteó. Aun se engrandeció contra el Príncipe de los ejércitos, y por él fue quitado el continuo sacrificio, y el lugar de su santuario fue echado por tierra... y echó por tierra la verdad, e hizo cuanto quiso y prosperó" (vv. 10-12).

Evidentemente, el primer ataque del cuerno pequeño es contra "el ejército del cielo y las estrellas" que, en este caso, es "el pueblo de los santos", tan igual como en 7:25, donde se afirma que el cuerno pequeño quebrantará a los santos del Altísimo. La declaración iy las pisoteó!", es lo mismo que se afirma en 7:19, donde Roma "las sobras hollaba con sus pies". Por lo tanto, el ataque aquí es contra el cuerpo de Cristo que es la Iglesia.

El período de tiempo profético, señalado por Daniel para que Roma, pudiera "quebrantar a los santos del Altísimo" es "hasta tiempo, y tiempos y medio tiempo" (7:25; 12:7). Del mismo modo, a Juan se le mostró que la mujer (iglesia), perseguida por el dragón, huiría al desierto donde
Dios la sustentaría por mil doscientos sesenta días (Ap 12:6) o cuarenta y dos meses (13:5). Históricamente, este ha sido el período más largo de persecución al cual Jesús hizo mención al declarar que ante la gran tribulación: “...si aquellos días no fuesen acortados, nadie seria salvo" (Mt 24:21-22).

Sin embargo, el ataque del cuerno pequeño se ensañaría "aun contra el Príncipe de los ejércitos”. Aquí se hace referencia a Cristo quien fue crucificado por la autoridad romana, representada por Poncio Pilato.

Si bien estos ataque ocurrieron en la tierra, la obra del cuerno pequeño llegaría hasta el cielo, esta vez en su ataque al centro de adoración del universo, el santuario celestial.

El ataque estuvo centrado en el "continuo sacrificio" o "tamid" que en hebreo significa "continuamente”. Aquí el continuo sacrificio de refiere al continuo ministerio sacerdotal de Cristo en el santuario celestial (He 7:25; 1 Jn 2:1).

Al quitar el continuo sacrifi- 
cio, Roma lo sustituyó por el sacrificio de la misa, el confesionario, desviando la atención de los hombres de la obra mediadora de Cristo en el santuario del cielo, a la de los mediadores humanos: sacerdotes, santos e imágenes, la virgen María, etc.

A esto mismo se refirió Pablo cuando habló de la gran apostasía que sucedería antes de la venida de Jesús, al declarar: "Nadie os engañe en ninguna manera; porque no vendrá sin que antes venga la apostasía, y se manifieste el hombre de pecado, el hijo de perdición, el cual se opone y se levanta contra todo lo que se llama Dios o es objeto de culto; tanto que se sienta en el templo de Dios como Dios, haciéndose pasar por Dios (2 Ts 2:3-4)

Como se ha podido apreciar, la obra de la primera bestia como agente de Satanás tuvo que ver con atacar el centro mismo de adoración del cielo, para instaurar lo que Jesús denominó la "abominación desoladora" (Mt 24:15; Dn 11:31). Por ello, cada sección del capítulo 13 de Apocalipsis enfatiza la obra de las dos bes- tias de hacer que todo el mundo adore $^{28}$ al dragón en la persona de sus agentes. Una prueba más de la forma cómo Roma se ensaña contra el "tamid" o continuo sacrificio de Cristo como único mediador en el santuario celestial, es haber canonizado a dos papas muertos (Juan XXIII y Juan Pablo II) el primero un papa liberal y el segundo un conservador, quienes ahora interceden ante Dios como mediadores del mundo católico. ${ }^{29}$

\section{Tercera sección- Descripción de la segunda bestia (vv. 11-12)}

"Después vi otra bestia que subía de la tierra; y tenía dos cuer-

${ }^{28} \mathrm{La}$ palabra griega adorar en gr. Proskyneoo se repite hasta en ocho ocasiones solo en el capítulo 13 y 14 de Apocalipsis, enfatizándose, de este modo, el tema del gran conflicto que es el tema de la adoración.

${ }^{29}$ Según los voceros del Vaticano 98 líderes mundiales y cerca de un millón de personas asistieron a la canonización de dos muertos quienes ahora son santos, corroborando, de este modo, la creencia de Roma en la doctrina de la inmortalidad del alma. 
nos semejantes a los de un cordero, pero hablaba como dragón. Y ejerce toda la autoridad de la primera bestia en presencia de ella, y hace que la tierra y los moradores de ella adoren a la primera bestia, cuya herida mortal fue sanada”.

La tercera sección, al igual que la primera, se inicia con el verbo "y vi" kai eidon para describir esta vez a otra bestia, con características que la conectan con la primera especialmente en cuanto a la autoridad, y cierra la sección con el verbo proskunesusin "adorarán" a la primera bestia v. 12 .

Nuevamente la pregunta es ¿Quién es esta segunda bestia con cuernos de cordero, pero que habla como dragón y cuál es el tiempo profético en el cual debía ejercer su función como agente del dragón?

Si se sigue el principio de que un texto debe ser interpretado en su contexto, la segunda bestia de Apocalipsis 13:11 debe ser ubicada por el tiempo en que la primera bestia sufrió la herida de muerte, pues su contexto mediato declaraba que "Si alguno lleva en cautividad, va en cautividad; si alguno mata a espada, a espada debe ser muerto", para referirse al cautiverio que el general Berthier le infligió al papa Pio VI, el 15 de febrero de 1798, como cumplimiento de la profecía $(13: 3,10)$.

En contraste con las cuatro bestias de Daniel 7, Apocalipsis 13:1 y la mujer ramera de Apocalipsis 17 que surgieron del mar, símbolo de pueblos, muchedumbres, naciones y lenguas (v. 15); la bestia de Apocalipsis 13:11 surgió de la tierra, de allí que la diferencia tiene que ser importante.

Cuando en profecías estrechamente relacionadas se contrastan tierra y mar, y el mar representa vastas poblaciones, se deduce que tierra representa una zona con población limitada. ${ }^{30}$

La descripción de esta bestia describe características de su forma de ser y de su obra. Esta segunda bestia identifica a una nación que no surge de otros pueblos, o de una convulsionada guerra como normalmente sucede. La

${ }^{30}$ Holbrook, Simposio sobre Apocalipsis, 2: 122. 
palabra gr. anabainon "subía” en griego se refiere a un crecimiento paulatino como el de una planta hasta estar formada. Esta nación "subía de la tierra", para indicar un lugar con población limitada, con el esfuerzo lento de su propio desarrollo humilde. Su poder inicial se reduce a "dos cuernos semejantes a los de un cordero", sin pretensiones de grandeza en contraste con otras que expresan ambiciones casi ilimitadas representadas con bestias agitadas y violentas.

Solo existe una nación que, en 1798 , surgía de la tierra con las características de un cordero, como lo señalo el historiador E. Morison.

Los Estados Unidos encajan en la profecía con precisión. En su surgimiento, esa nación reveló cualidades semejantes a las de un cordero, y surgió en una zona relativamente despoblada, la tierra, en contraposición al bullente y atestado mar del viejo mundo. Los americanos indígenas vagaban por las riberas y las llanuras cuando llegaron los nuevos colonizadores, pero en número escaso. Un cálculo documentado sitúa su población en, aproximadamente, un millón esparcido por los casi diez millones de kilómetros cuadrados, que después se convirtieron en los Estados Unidos. ${ }^{31}$

Esta afirmación ya había sido hecha por Elena G. de White, cuando Estados Unidos apenas iniciaba la era de la industrialización. White declaró:

“Cuál era en 1798 la nación del nuevo mundo cuyo poder estaba entonces desarrollándose, dándose visos de ser una nación fuerte y grande, y de llamar la atención del mundo? La aplicación del símbolo no admite duda alguna. Una nación y solo una responde a los datos característicos de esta profecía; no hay duda de que se trata aquí de los Estados Unidos de Norteamérica. ${ }^{32}$

Los "dos cuernos" de su poder describen donde se sustenta

${ }^{31}$ Samuel Eliot Morison, The Oxford History of the American People. Citado por Holbrook, ed. Simposio sobre Apocalipsis, 2: 125.

${ }^{32}$ Elena G. de White, El conflicto de los siglos (Florida, EE.UU: Asociación Publicadora Interamericana, 2006), 345. 
esta nación. La base de su poder está en la libertad política y religiosa (separación de iglesia y estado) que su constitución protege sin discriminación alguna, pero en su forma de hablar Juan vio que "hablaba como dragón". Esta es una extraña contradicción de su grandeza, porque no siempre fue así. La gran pregunta es ¿por qué?, y la respuesta es por el poder que ostenta hoy en día de ser la nación más poderosa de la tierra, capaz de intervenir con su poderío en cualquier país del mundo, aun contra la oposición de las Naciones Unidas.

\section{Cuarta sección- Explicación de lo que hace la segunda bestia vv. 13-18}

"También hace grandes señales, de tal manera que aun hace descender fuego del cielo a la tierra delante de los hombres. Y engaña a los moradores de la tierra con las señales que se le ha permitido hacer en presencia de la bestia, mandando a los moradores de la tierra que le hagan imagen a la bestia que tiene la herida de espada, y vivió. Y se le permitió infundir aliento a la imagen de la bestia, para que la imagen hablase e hiciese matar a todo el que no la adorase, Y hacía que a todos, pequeños y grandes, ricos y pobres, libres y esclavos, se les pusiese una marca en la mano derecha, o en la frente; y que ninguno pudiese comprar ni vender, sino el que tuviese la marca o el nombre de la bestia, o el número de su nombre. Aquí hay sabiduría. El que tiene entendimiento, cuente el número de la bestia, pues es número de hombre. Y su número es seiscientos sesenta y seis".

La cuarta sección, al igual que la segunda, es una explicación de lo que hace la segunda bestia, en este caso señales para engañar a los moradores de la tierra, mandando poner una marca en la frente o en la mano a los que no tienen la marca de la bestia o el número de la bestia, y cierra la sección con el verbo que ordena matar a todo el que no "adore" proskunesoosin a la primera bestia y a su imagen. 
La profecía anuncia de dónde proviene su poder y la respuesta es que "ejerce toda la autoridad de la primera bestia” (v. 12). Por tanto, siendo que la primera bestia recibió toda la autoridad del dragón, el poder y la autoridad de esta segunda bestia le es concedido también por el mismo dragón, por medio del espiritismo sofisticado y culto, al punto que "hace grandes señales...hace descender fuego del cielo...Y engaña a los moradores de la tierra”. Estas tienen que ser señales que asocien sus acciones con Dios, legitimizando ante la tierra su dominio, como son su intervención en Vietnam, en Atganistan, en Irak, etc, y todo esto "en presencia de ella (de la primera bestia).

El siguiente paso es que en uso de la autoridad que ejerce, manda "a los moradores de la tierra que le hagan imagen ${ }^{33}$ a la bestia". Esto es precisamente lo que hoy se está

${ }^{33} \mathrm{La}$ evidencia más clara de un poder religioso que se hizo una gran imagen para poder ser adorado a través de ella lo constituye el poder de Babilonia (Dn 3) quien, en su unión de iglesia y estado, dio un decreto de muerte contra todo el que no adorase a su imagen. gestando con la gran coalición de iglesias que se unen con el poder del estado, para exigir que el estado legisle en asuntos religiosos. $\mathrm{Al}$ respecto White declaró:

"Cuando las iglesias principales
de los Estados Unidos, uniéndose
en puntos comunes de doctrina, in-
fluyan sobre el estado para que
imponga los decretos y las institu-
ciones de ellas, entonces la Amé-
rica protestante habrá formado
una imagen de la jerarquía roma-
na, y la inflicción de penas civiles
contra los disidentes vendrá de
por sí sola". ${ }^{34}$

Este acto de unión política, entre la iglesia y el estado, se inició entre Estados Unidos y Roma cuando, en marzo de 1984, el presidente Ronald Reagan nombró a William A. Wilson embajador ante la ciudad del Vaticano, el senado aprobó rápidamente el nombramiento por 81 votos contra 13 .

Estas medidas para violentar las conciencias serán muy parecidas a las que utilizó Roma en el pasado en su unión de la iglesia con el esta-

${ }^{34}$ White, 498 
do. El uso de la fuerza para destruir a los que se oponen, es lo que está haciendo ya la nación americana en presencia de Roma. Por tanto, qué significa la orden dada por estas bestias confabuladas de "que a todos ...se les pusiese una marca en la mano derecha, o en la frente. Y que ninguno pudiese comprar ni vender, sino el que tuviese la marca o el nombre de la bestia, o el número de su nombre".

Siendo que la sección de los capítulos 12-14 de Apocalipsis se introducen con una escena del santuario celestial, donde Juan vio que “...el templo de Dios fue abierto en el cielo, y el arca de su pacto se veía en el templo" (11:19). Se está refiriendo al lugar santísimo, donde estaba el arca que contenía los diez mandamientos.

La siguiente escena, del capítulo 12 de Apocalipsis, se cierra con la mención del remanente (resto) quienes son caracterizados como personas respetuosas de los mandamientos (v. 17), para diferenciarlos de los quebrantadores de los mandamientos, quienes serán los que recibirán la marca de la bestia.
Siendo que el tema de los capítulos 12-14 es la adoración en el gran conflicto, otra vez el profeta Daniel muestra que lo que estaría en juego en el gran conflicto entre Cristo y Satanás sería la ley de Dios, de allí el atentado que hizo el dragón a través de su agente Roma al cambiar "los tiempos y la ley" (Dn 7:25), específicamente en lo tocante al cambio del sábado por el domingo que Roma misma admite haber cambiado en honor a la resurrección de Cristo. ${ }^{35}$

No existe, entonces, dudas de que la marca de la bestia tiene que ver con el falso día de reposo (el domingo) como señal de autoridad impuesta por Roma, en contraposición al sábado como señal de autoridad entre Dios y su pueblo, tal como lo corrobora la Biblia (Ez 20:12, 20; Ex 31:12-17). White así lo confirma:

"Cuando la observancia del domingo sea impuesta por la ley, y que el mundo sea ilustrado respecto a la obligación del verda-

${ }^{35}$ Isidro Sala Ribera, ed. Catecismo de la Iglesia Católica (Lima: Librería Bruño, 1993), 211-214. 
dero día de descanso, entonces el que transgrediere el mandamiento de Dios para obedecer un precepto que no tiene mayor autoridad que la de Roma, honrará con ello al papado por encima de Dios: rendirá homenaje a Roma y al poder que impone la institución establecida por Roma: adorará a la bestia y su imagen. Cuando los hombres rechacen, entonces, la institución que Dios declaró ser el signo de su autoridad, y honren en su lugar lo que Roma escogió como signo de su supremacía, ellos aceptarán de hecho el signo de la sumisión a Roma, "la marca de la bestia". ${ }^{36}$

Queda confirmado, por tanto, que "la marca de la bestia" identifica al falso día de reposo (el primer día de la semana o domingo), que Roma sancionó en honor a la resurrección de Cristo, pero sin ningún apoyo bíblico, sino valiéndose de la autoridad que le dio el dragón, contrariando el mandamiento del sábado dado por Dios desde la creación ${ }^{37}$, y sancionado por Jesucristo. ${ }^{38}$

\footnotetext{
${ }^{36}$ White, 502-3.

${ }^{37}$ Génesis 2:1-3; Éxodo 20:8-11.

${ }^{38}$ Mateo 5:17-20; Lucas 4:16.
}

Ahora, tocante a la declaración de Juan: "Aquí hay sabiduría. El que tiene entendimiento, cuente el número de la bestia, pues es número de hombre, y su número es seiscientos sesenta seis". La sabiduría a la que aquí se hace mención es la divina, tal como Pablo lo declara cuando afirma que las cosas de Dios "...se han de discernir espiritualmente”. ${ }^{39}$

Lo que debe notarse es que la bestia ya ha sido identificada, por tanto, el descubrir el significado del número será una confirmación y una advertencia.

Históricamente uno de los primeros en escribir sobre el tema fue Ireneo (130-202 d. C.), identificando a la bestia como el anticristo. Creía que los valores numéricos de las letras de su nombre sumarían 666. Pero, al mismo tiempo, previno que "es, por lo tanto, más seguro y menos peligroso esperar el cumplimiento de la profecía, que hacer conjeturas y buscar aquí y allí nombres que puedan presentarse, pues pueden presentarse muchos nombres que poseen el número mencionado". 40

\footnotetext{
${ }^{39} 1$ Corintios 2:14.

${ }^{40}$ Ireneo, Contra herejías v.30.3.
} 
Si bien es cierto que este número ha sido aplicado a muchos otros personajes, la profecía señala que es "el número de la bestia" y a la vez "el número de su nombre". Por tanto, una interpretación que se divulgó, en el período que siguió a la reforma, fue que 666 representa o equivale al valor de las letras o nombre en latín Vicarivs Filii Dei que significa "vicario del Hijo de Dios". La suma del valor de estas letras da como resultado 666.

Queda claro que cada una de las secciones propuestas se inicia con una descripción de las bestias, y la explicación de lo que cada una de ellas hace o recibe del dragón, culminando cada sección con la acción de adorar, impuesta por la triple unión entre el dragón, la primera y la segunda bestia.

\section{El uso de Elena G. de White de Daniel y Apocalipsis}

Elena G. de White reconoce que, en los libros de Daniel y Apocalipsis, hay un desarrollo histórico desde los días de Daniel y de Juan, hasta el establecimiento del reino eterno de Dios.

"En el Apocalipsis son presentadas las cosas profundas de Dios. Sus verdades son dirigidas a aquellos que viven en los últimos días de la historia de esta tierra, así como para aquellos que vivieron en los días de Juan. Algunas de las escenas descritas en esta profecía han ocurrido en el pasado, otras están teniendo cumplimiento ahora y otras para el cierre del gran conflicto entre el bien y el mal, y algunas revelan los triunfos y gozos de los redimidos en la tierra nueva". ${ }^{41}$

"La luz que Daniel recibió de Dios fue dada especialmente para estos últimos días; las visiones que él recibió, junto al río Ulai, están ahora en proceso de cumplimiento y todos los eventos predichos, pronto vendrán a suceder". ${ }^{42}$

${ }^{41}$ Elena G. de White, The Acts of the Apostles (Washington, DC,:Review and Herald, 1957), 584-85.

${ }^{42}$ Ibíd., 112-13. 


\section{Conclusiones}

El uso del principio de interpretación historicista, usado para el análisis de Apocalipsis 13 está sólidamente basado en los pasajes de Daniel (7 y 8), Jesús (Mt 24) y Pablo (2 Ts 2), especialmente en lo referido al tiempo profético de los 1260 días o años de supremacía papal (538-1798 d. C.) Daniel 7:25, 12:7, Apocalipsis 11:2, 12:6, 13:5, lo que ha permitido identificar a la primera bestia de Apocalipsis 13 1-10 con el poder del imperio de Roma, en su fase pagana y papal.

Gramaticalmente, Apocalipsis 13 es parte de la sección que se inicia en 11:19-14:20, donde el tema principal del gran conflicto es el tema de a quién adorar, cómo adorar y por qué adorar, prerrogativa que el dragón y sus agentes le disputan a Dios como Creador en lo tocante a su ley y, específicamente, al sábado como monumento recordativo de la creación.

Las cuatro secciones en las cuales ha sido dividido, el capítulo 13 de Apocalipsis, se carac- terizan por un paralelismo propio del pensamiento hebreo, donde la primera sección describe lo que Juan vio acerca de la primera y la segunda bestia, y la segunda sección es el accionar de las cosas que hacen las dos bestias como agentes de Satanás, en lo tocante a obligar al mundo a adorar a la primera bestia.

La identificación de la primera bestia (Ap 13), con el cuerno pequeño de Daniel 7 y 8 , es una correspondencia exacta de la triple obra hecha contra Dios respecto a blasfemar contra Dios, perseguir a sus santos, pero sobre todo en cuanto al ataque contra el tamid o la continua obra mediadora de Cristo en el santuario celestial.

La segunda bestia no tiene comparación en la profecía de Daniel, razón por la cual esta solo ha podido ser identificada en el contexto del tiempo profético de la herida de la primera bestia ocurrida en 1798 (Ap 13:3). La única nación que surgía de la tierra con cuernos de cordero, al final de este período de tiempo profético, es los EE. UU. de Norteamérica. 
La obra final de la segunda bestia, como agente del dragón, será hecha en estos últimos días, en relación a hacer una imagen para obligar al mundo a adorar a la primera bestia, a través de la imposición de la marca de la bestia (el domingo como falso día de reposo) en la mano derecha o en la frente, dividiendo al mundo en solo dos grupos, los que tengan el sello de Dios (el sábado como señal de lealtad a Dios y a su ley), y los que reciban la marca de la bestia (el domingo como señal de lealtad a Roma).

Siendo que la Iglesia Adventista del Séptimo Día, por sus carac- terísticas que la identifican como la Iglesia remanente de la profecía de Apocalipsis 12:17; 14:12 y 19:10; Dios espera que cada uno de sus miembros se comprometa en la obra de pregonar el último mensaje de los tres ángeles (Ap 14:6-12), advirtiendo al mundo acerca de la obra astuta y sigilosa del dragón (Satanás) a través de sus agentes (la Roma papal y los EE. UU. de Norteamérica), para imponer la marca de la bestia (el domingo como falso día de reposo) como señal de autoridad y de adoración a todo el mundo. 